\title{
Surgical Treatment of Ingrown Toenail by Nail Fold Resection without Matricectomy
}

\author{
Ahmed Mohammad Ahmed Mohammad*, Mohammad Elsayed Radwan, Mohammad \\ Arafat Abdel-Maksoud \\ Department of General Surgery, Faculty of Medicine, Al-Azhar University, Cairo, Egypt \\ *Corresponding author: Ahmed Mohammad Ahmed Mohammad, E-mail: $\underline{\text { midoo_sedeek@yahoo.com, Tel: }}$ \\ $\underline{01022562021}$
}

\begin{abstract}
Background: ingrown toenail is a common condition. Although many methods for treatment are available, there is no consensus on the optimal treatment.

Aim of the study: to evaluate surgical correction of ingrown toenails via soft-tissue excision of the nail folds with preservation of the nail and its matrix.

Patients and Methods: This study includes one hundred (100) patients suffering from ingrowing toenail; these patients were enrolled in a combined prospective study and had a retrospectively gathered outcome analysis at the department of surgery, AL-Azhar University Hospital from October 2017 to October 2018.

Results: significantly short operative time was recorded. Postoperative wound complications occurred in $15.7 \% \%$ of patients. All cases presented in grade I (33 cases), only one case, symptoms and signs of grade I recurred 1 months after operation (recurrence rate $0.9 \%$ ). The 27 cases presented in grade II ingrown toenails, symptoms and signs recurred in 7 cases (recurrence rate $6.5 \%$ ). The 48 cases presented in grade III, symptoms and signs recurred in 10 cases (recurrence rate $9.2 \%$ ). The recurrence rate in all cases was 18 cases $(16.66 \%)$.

Conclusion: nail fold excision of ingrowing toenail without matrisectomy is considered as an effective and safe method for ingrown nail treatment.

Keywords: matrisectomy, ingrowing toenail.
\end{abstract}

\section{Introduction}

Ingrown toenails are frequently encountered in clinical practice, with an estimated 10000 new cases per year in the United Kingdom. Young men are most frequently affected, and the associated morbidities have significant economic impact, secondary to decreased mobility and work absenteeism. Currently, a wide variety of treatment options exist; however, they are associated with poor cosmetic results, low rates of patient satisfaction and high rates of recurrence $^{(\mathbf{1})}$.

Initial treatment of an ingrown toenail, or onychocryptosis, is conservative management, including avoiding tight- fitting shoes and using warm water baths and soft compresses ${ }^{(\mathbf{1})}$.

Surgical intervention is ultimately required in refractory cases. Many approaches have been described, with most targeting the nail as the causative agent. Partial nail avulsion coupled with chemical destruction of the nail matrix (matricectomy) with phenol remains the most preferred surgical technique ${ }^{(2)}$.

Vandenbos and Bowers ${ }^{(3)}$ suggested that pressure necrosis of the soft tissue surrounding the nail contributes to the pathogenesis of ingrown toenails. Indeed, increased nail-fold skin width in patients with ingrown toenails, greater weight- 
bearing on the soft tissue of the nail fold and repetitive rotation of the toe have all been suggested to be important contributing factors.

A study by Pearson and colleagues (3) helped to draw the focus away from the nail as the causative agent. They reported no differences in the shape of the toenails among patients with ingrown toenails and healthy controls. It is tempting to speculate that the current surgical interventions that target the nail (i.e., nail avulsion and matricectomy) do not directly address the

\section{Aim of the study:}

This study was done to evaluate surgical correction of ingrown toenails via soft-tissue excision of the nail folds with preservation of the nail and its matrix.

\section{Patients and methods}

This study include one hundred (100) patients suffering from ingrowing toenail; these patients were enrolled in a combined prospective study and gathered outcome analysis at the department of surgery, AL-Azhar University Hospital from October 2017 to October 2018.

\section{Preoperative work up}

All Patients were subjected to:

* History Taking

* Clinical Examination

* Laboratory investigations:

- Complete blood count.

- Liver function tests.

- Kidney function tests.

Preoperative care

Random blood sugar.

A patient record form was prepared, and patients' age, sex, duration of symptoms, preoperative antibiotic use, previous treatments, return to work, complications such as wound discharge causative soft-tissue pathology. In this study, They used a modification of the surgical approach described by Vandenbos and Bowers ${ }^{(3)}$ in a large patient population to show that soft-tissue nail-fold resection leads to surgical correction of ingrown toenails. His approach yields excellent cosmetic results with no recurrences and high rates of patient satisfaction. The treatment is cost effective, technically simple and can be performed easily in any physician's office ${ }^{(4)}$.

A comprehensive assessment program was carefully structured so that a disciplined routine followed in each patient. All patients were preoperatively and postoperatively evaluated .

Ethical approval was taken from general surgery department ethical committee and written consent was taken from every patient after explanation of all details of the operation, advantages, disadvantages, realistic expectations, and all the possible intra-operative, early and late post-operative complications.

\section{Inclusion criteria}

1- Age between 16 and 52 years .

2- History of failure of conservative treatment for more than one year.

and infection and wound care time were recorded. All patients were admitted to hospital the same day of surgery and operated under local anesthesia.

\section{Surgical techniques:}

We perform the operation of ingrowing toenail by soft tissue nail fold excision without matrisectomy. Surgical applications were performed by the same surgeon in the outpatient operating room. The toe was washed with povidone-iodine and covered sterilely. Digital nerve block anesthesia was applied with $2 \%$ adrenaline-free lidocaine. The lateral side of a sterile surgical glove was cut in strips 
$1 \mathrm{~cm}$ in width. A strip was wrapped in a circular fashion from the distal of the big toe to its proximal and rolled around itself a few times at the proximal. The big toe was exposed by cutting the strip from the distal and keeping it intact at the proximal. Thusly, tourniquet application was performed and hemostasis achieved. On the ingrown side of the nail plate, a 6- to 7$\mathrm{mm}$ vertical skin incision was performed on the proximal nail fold in order to remove the skin over the nail matrix. The cutting edge of the surgical blade was reversed, as to face the foot dorsal. Granulation tissue was cleaned with a curette. Skin over the nail matrix was pulled sideways. The lateral part of the matrix was totally exposed. The wound was covered with sterile dressing, and the tourniquet was removed.

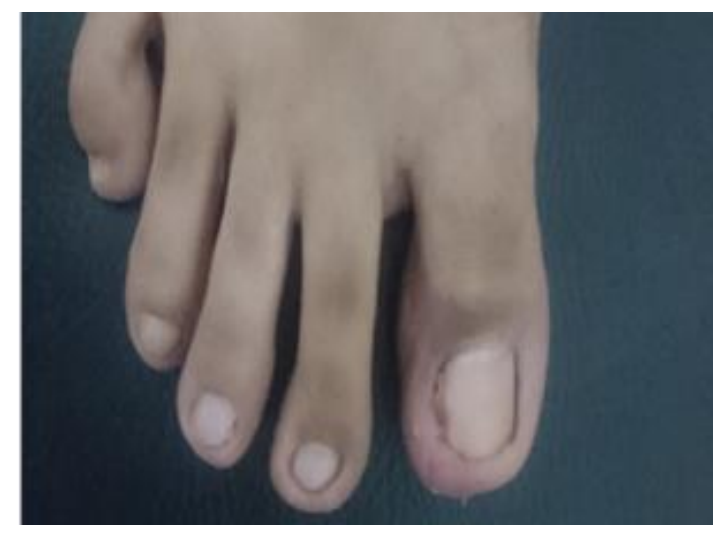

Fig (1): Preoperative view of the ingrown nail

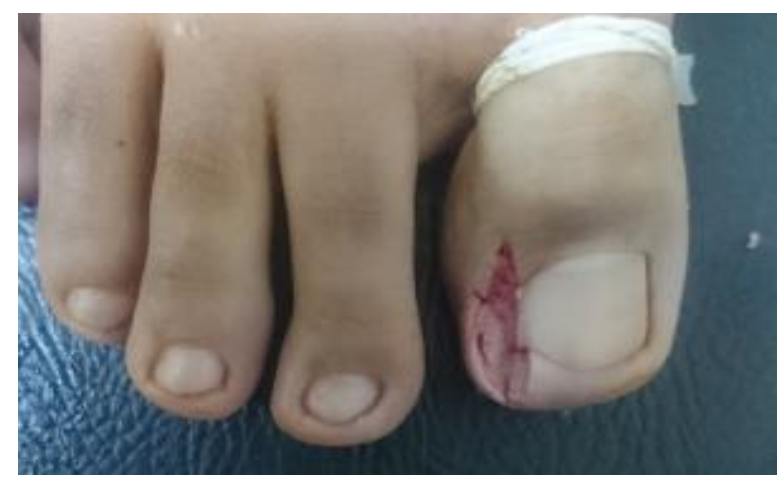

Fig (2): Immediately after soft tissue resection without matricectomy. 
Fig (3): day 7 view patient's serous fluid deposition can be seen

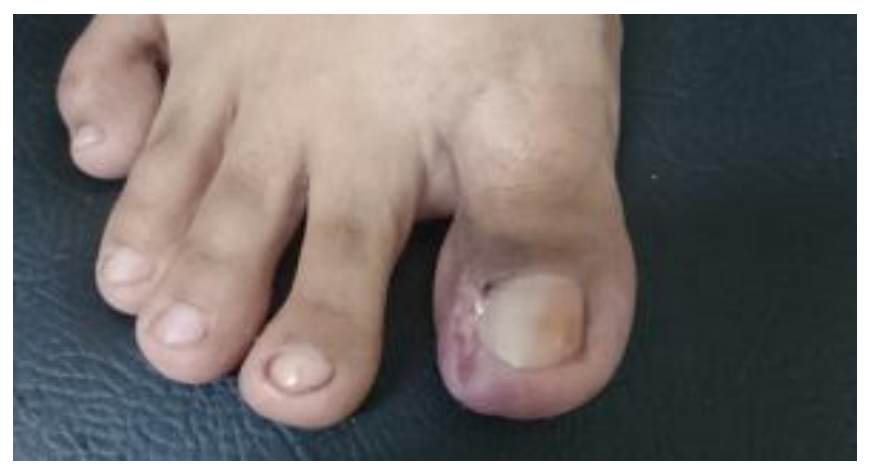

Postoperative of the same toes. Edema and

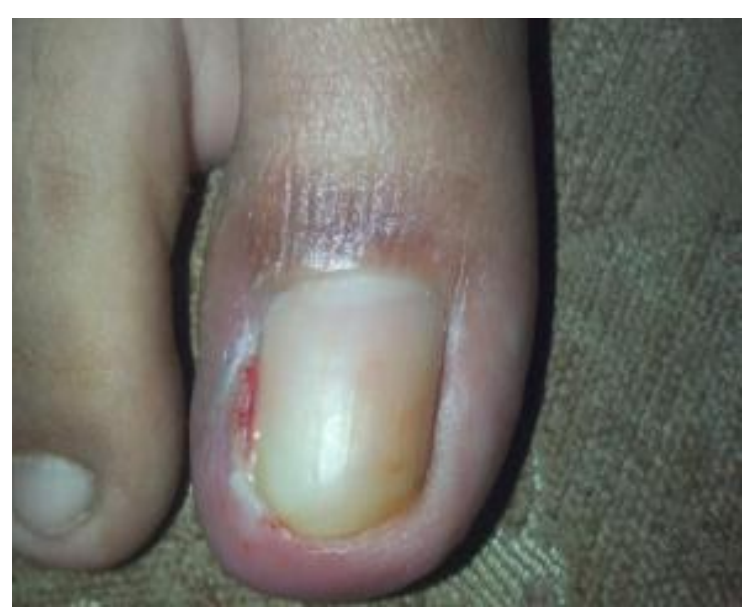

Fig (4): Postoperative month view of the same patient's toes

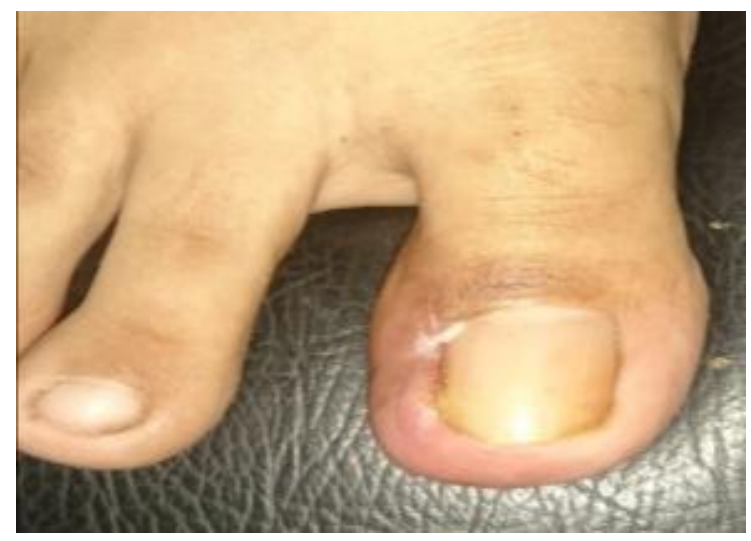

Fig (5): View of the same toe at 2-month follow-up. 


\section{Post-operative care}

Patients were advised to take acetaminophen when they had pain. Systemic antibiotics were not administered to any patient. Wounds of the patients were followed up at the second, fifth, and eleventh days postoperatively, at which point they were removed. Patients were asked to return for follow-up at the third and sixth weeks postoperatively, as well as the third and sixth months, after which they were to return at 6-month intervals. Presence of pain, infection and drainage was investigated at the 6-week follow-up. Recovery time was accepted when improvement of edema in the toe, loss of inflammatory changes, and epithelization in the wedge resection were observed and patients were able to wear their usual shoes. Repeating ingrown nails, painful nail edge dystrophies. Patients' satisfaction with the general appearance of their nails was investigated at the 6-month follow-up.

\section{Results}

A comprehensive assessment program was carefully structured so that a disciplined routine is followed in each patient. All patients were preoperatively and postoperatively evaluated .

\section{Pre- operative Data:}

1- Age and Sex

100 patients (108 cases) with ingrown toenail were treated as outpatients. The mean age at presentation was 26.45 years old, ranging from 16 to 52 years old. The male patients were 68 (i.e. 71 cases) and the female patients were 32 (i.e. 37 cases). The male: female ratio was 2:1 (table 1 and Fig. 6).

Table (1): age and sex distribution

\begin{tabular}{|c|c|c|c|c|c|c|c|c|c|}
\hline & \multirow{2}{*}{$\begin{array}{l}\text { No. of } \\
\text { patients }\end{array}$} & \multirow{2}{*}{$\begin{array}{l}\text { Age } \\
\text { Range/years }\end{array}$} & \multicolumn{6}{|c|}{ Decade of life } & \multirow{2}{*}{$\begin{array}{l}\text { Mean } \\
\text { Age/ } \\
\text { years }\end{array}$} \\
\hline & & & $1 \mathrm{st}$ & $2^{\text {nd }}$ & $3^{\text {rd }}$ & $4^{\text {th }}$ & $5^{\text {th }}$ & 6th & \\
\hline Male & 68 & $17-52$ & 0 & 25 & 27 & 8 & 7 & 1 & 27.5 \\
\hline Female & 32 & $16-32$ & 0 & 17 & 13 & 2 & 0 & 0 & 21.7 \\
\hline Total & 100 & $16-52$ & 0 & 42 & 40 & 10 & 7 & 1 & 26.45 \\
\hline
\end{tabular}

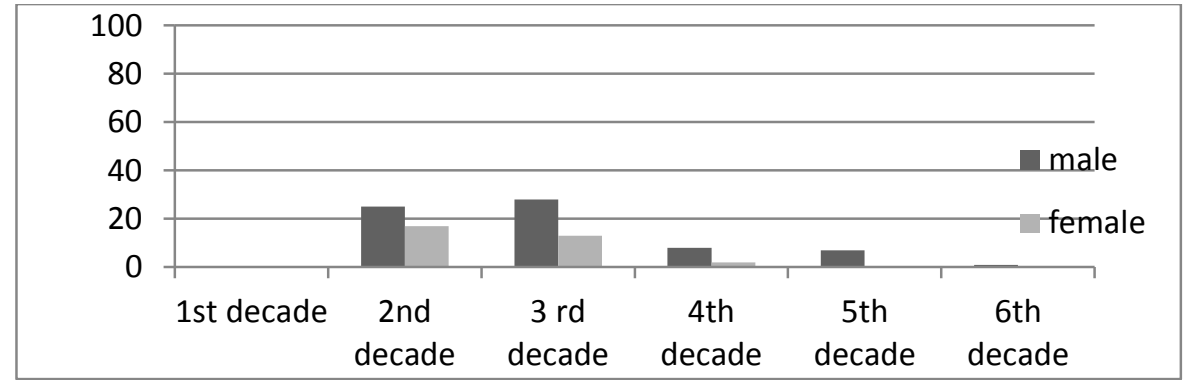

Fig (6): age and sex distribution

2- Causes of ingrown toenail:

20 patients $(20 \%)$ i.e. 22 cases $(20.3 \%)$ were

As regards the etiology of ingrown founded to have incurvated toenails and 10 toenails, 40 patients $(40 \%)$ i.e. 42 cases patients (10\%) i.e. 12 cases $(11.1 \%)$ were $(38.8 \%)$ gave a history of improper nail founded to have hyperhidrosis (table 2 and Fig. trimming, 30 patients $(30 \%)$ i.e. 32 cases 7$)$.

$(29.6 \%)$ gave a history of wearing tight shoes, 
Table (2): Causes of ingrown toenail

\begin{tabular}{|l|l|l|l|l|}
\hline Causes & $\begin{array}{l}\text { Improper } \\
\text { cutting }\end{array}$ & wearing tight & incurvated toena & hyperhidrosis \\
\hline Number of cases 108 & 42 & 32 & 22 & 12 \\
\hline Percentage \% & $38.8 \%$ & $29.6 \%$ & $20.3 \%$ & $11.1 \%$ \\
\hline
\end{tabular}

\section{causes of ingrowing toenail}

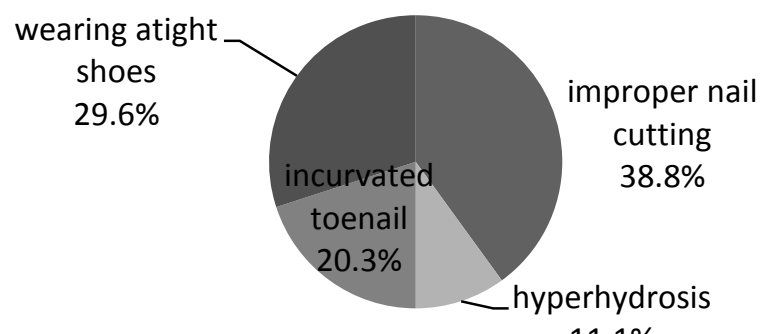

$11.1 \%$

Fig (7): Causes of ingrown toenail

\section{3- Grades of ingrown toenail}

33 cases (30.5\%) presented with stage 2 ingrown toenail, 27 cases (25\%) presented with stage II ingrown toenail and 48 cases (44.4\%) presented with stage III (table 3) (Fig. 8).

Table (3): grades of ingrown toenail

\begin{tabular}{|l|l|l|l|}
\hline Grade & I & II & III \\
\hline Number of cases 108 & 33 & 27 & 48 \\
\hline Percentage \% & $30.5 \%$ & $25 \%$ & $44.4 \%$ \\
\hline
\end{tabular}

\section{grades of ingrowing toenail}

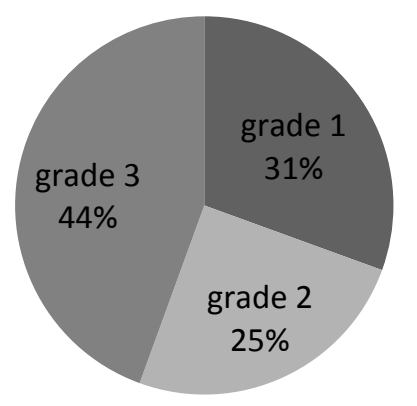

Fig (8): grades of ingrown toenail.

4- Foot affection:

Right foot was affected in 50 patients (50\%) and left foot was affected in 46 patients (46\%) and both feet were affected in 4 patients (4\%) (Table 4 and Fig. 9). 
Table (4): foot affection of ingrown toenail

\begin{tabular}{|l|l|l|l|}
\hline Side & Right & Left & Both \\
\hline Number of patient (100) & 50 & 46 & 4 \\
\hline Percentage \% & $50 \%$ & $46 \%$ & $4 \%$ \\
\hline
\end{tabular}

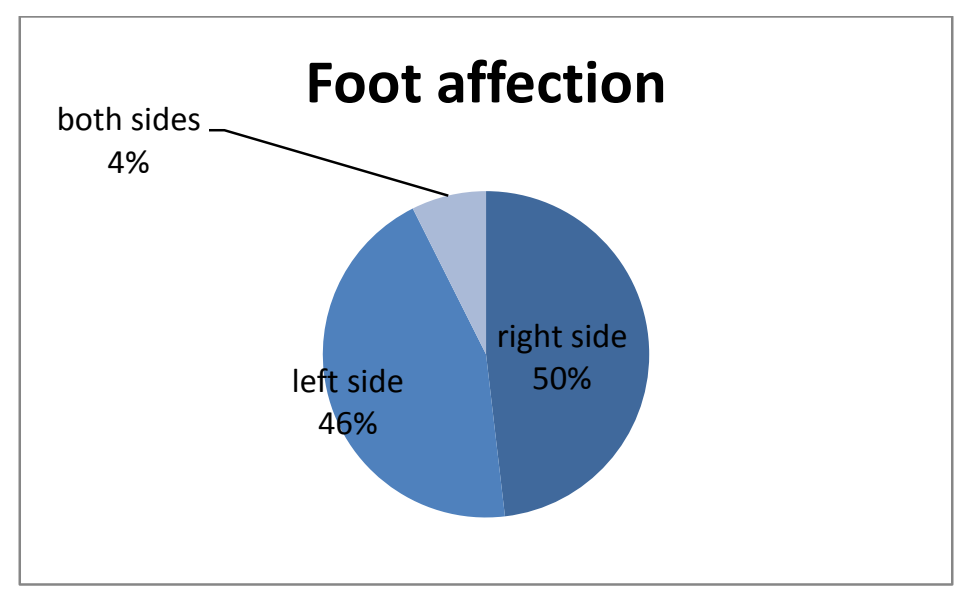

Intra operative data

Fig (9): foot affection of ingrown toenail

Duration of surgery

The mean time of surgery during operation was $15 \pm 5.6$ minutes.

\section{Postoperative complications:}

\section{(A) Bleeding}

Post-operative bleeding was observed in 7 cases and 101 cases had no post-operative bleeding (table 7 and Fig. 10).

Table (7): post-operative bleeding

\begin{tabular}{|c|l|l|}
\hline Bleeding & Yes & No \\
\hline Number of cases (108) & 7 & 101 \\
\hline
\end{tabular}

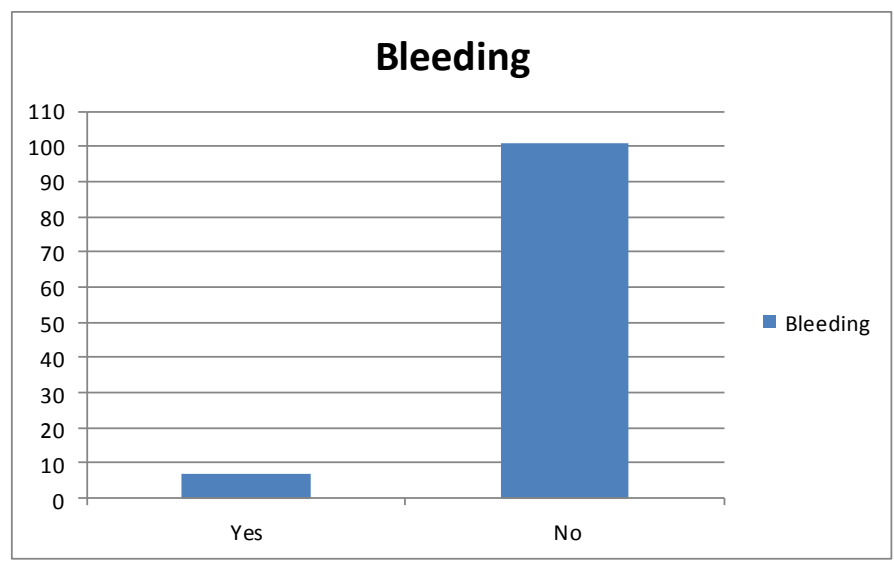

Fig (10): post-operative bleeding.

\section{(B) Post-operative infection}

Postoperatively, 17 (15.7\%) got inflammation and infection in their folds and $91(84.2 \%)$ cases had not any problems (table 8 and Fig. 11). 
Table (8): post-operative infection.

\begin{tabular}{|l|l|l|}
\hline Infection & Yes & No \\
\hline Number of cases (108) & 17 & 91 \\
\hline
\end{tabular}

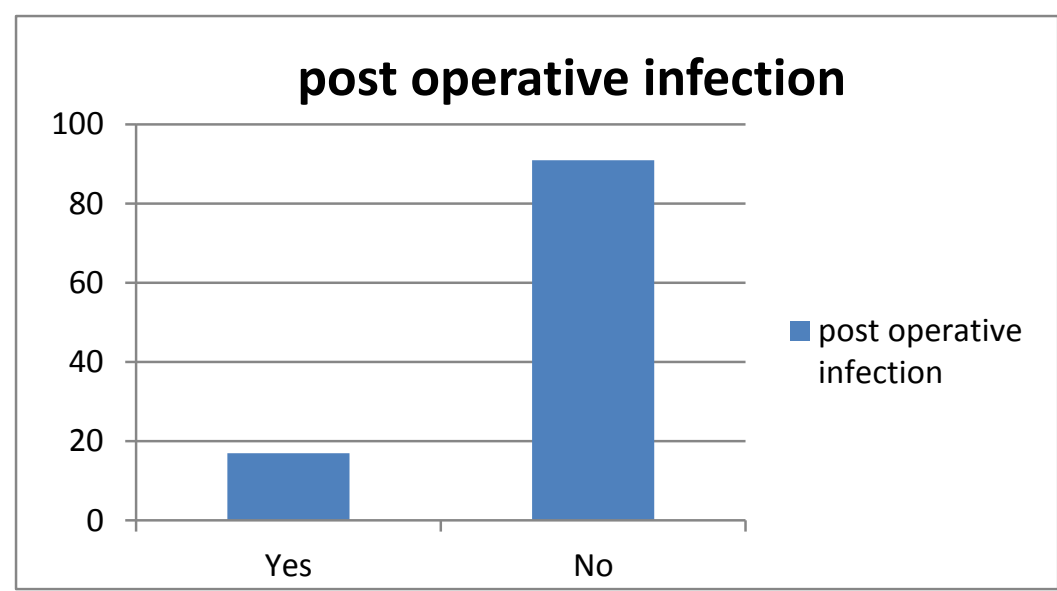

(C) Post-operative discharge

Fig (11): post-operative infection

Post-operative discharge was observed in 95 cases and 13 cases had no post operativedischarge.

Table (9): post-operative discharge

\begin{tabular}{|l|l|l|}
\hline Discharge & Yes & No \\
\hline Number of cases (108) & 95 & 13 \\
\hline
\end{tabular}

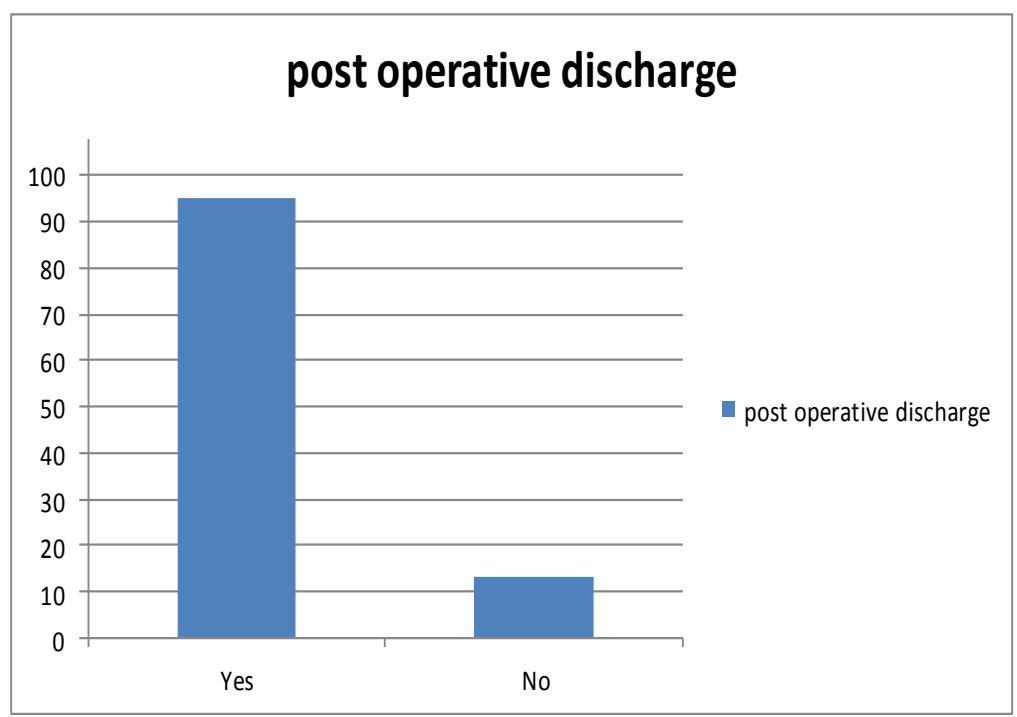

Fig (12): post-operative discharge

\section{1- Patient satisfaction}

Cosmetic results were good in 90 cases $(83.33 \%)$ who cooperated with the doctor and obey his instruction to renew the cotton wool and his advice on footwear and foot hygiene, especially nail trimming as the treatment regimen and was acceptable for the residual 18 cases (16.66 \%) (Table 9 and Fig. 13). 
Fig (13): patient satisfaction

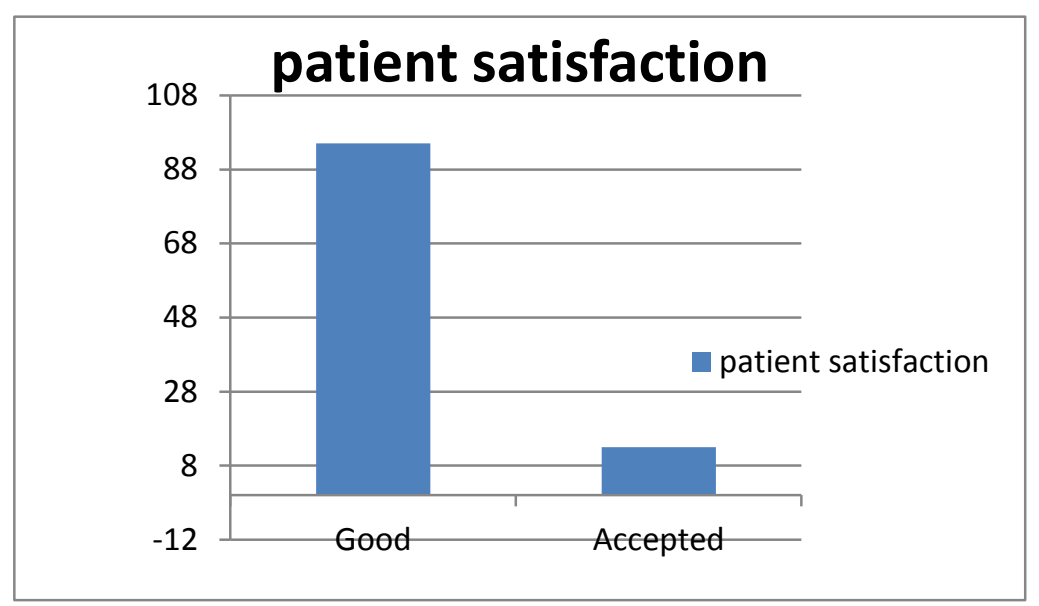

Table (10): patient satisfaction

\begin{tabular}{|l|c|c|}
\hline Patient satisfaction & Good & Accepted \\
\hline Number of cases (108) & 90 & 18 \\
\hline
\end{tabular}

\section{4- Time of healing}

All cases presented in grade I and treated by nail fold excision without matricectomy (33 cases) were cured within 13 days (12-18) days. The 27 cases presented in grade II ingrown toenails and treated by nail fold excision without matricectomy cured within 21 days (17-29) days. The 48 cases presented in grade III and treated by nail fold excision without matricectomy cured within 35 days (25-42) days. The mean time of healing was 24.77 days (table 11 and Fig. 14).

Table (11): time of healing

\begin{tabular}{|c|c|c|c|c|}
\hline $\begin{array}{l}\text { Grade of } \\
\text { ingrowing toenail }\end{array}$ & $\begin{array}{l}\text { Number of } \\
\text { Cases (108) }\end{array}$ & $\begin{array}{l}\text { Percentage } \\
(\%)\end{array}$ & $\begin{array}{l}\text { Time of } \\
\text { Healing (Days) }\end{array}$ & $\begin{array}{l}\text { Mean time of healing } \\
\text { (Days) }\end{array}$ \\
\hline Grade 1 & 33 & $30.5 \%$ & 13 & 24.77 \\
\hline Grade 2 & 27 & $25 \%$ & 21 & \\
\hline Grade 3 & 48 & 44.4 & 35 & \\
\hline
\end{tabular}

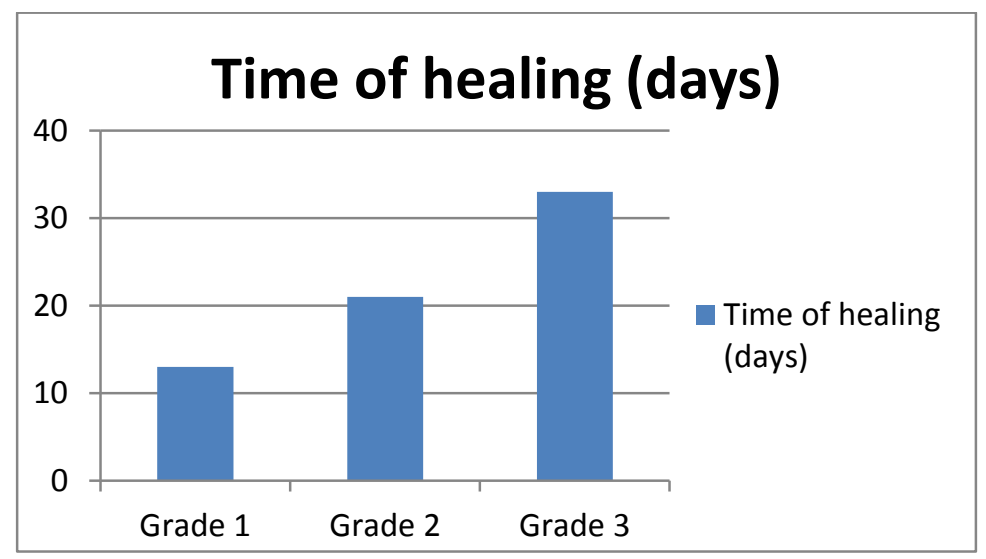

Fig (14): time of healing

\section{Recurrence rate:}

All cases presented in grade I and treated by nail fold excision without matricectomy (33 cases), only one case, symptoms and signs of grade I recured 1 months after operation and this patient was treated with the same regimen (recurrence rate $0.9 \%$ ). The 27 cases presented in grade II ingrown toenails and treated by nail fold excision without matricectomy, symptoms and signs recurred in 7 cases (recurrence rate 6.5\%). The 48 
cases presented in grade III and treated by nail fold excision without matricectomy, symptoms and signs recurred in 10 cases (recurrence rate 9.2\%). The recurrence rate in all cases was 18 cases (16.66\%). Recurrence was observed in the form of spicule growth in the nails. These results were reached because there were no change in the nail shape nor in the fold shape (table 12 and Fig. 15).

\begin{tabular}{|l|l|l|c|}
\hline \multicolumn{1}{|c|}{ Table (12): recurrence rate } \\
\hline Recurrence & $\begin{array}{l}\text { Number of } \\
\text { cases }\end{array}$ & $\begin{array}{l}\text { Percentage } \\
\text { recurrence }\end{array}$ & Total \\
\hline grade 1 & 1 & $0.9 \%$ & $18(16.6 \%)$ \\
\hline grade 2 & 7 & $6.5 \%$ & \multirow{2}{*}{} \\
\hline grade 3 & 10 & $9.2 \%$ & \\
\end{tabular}

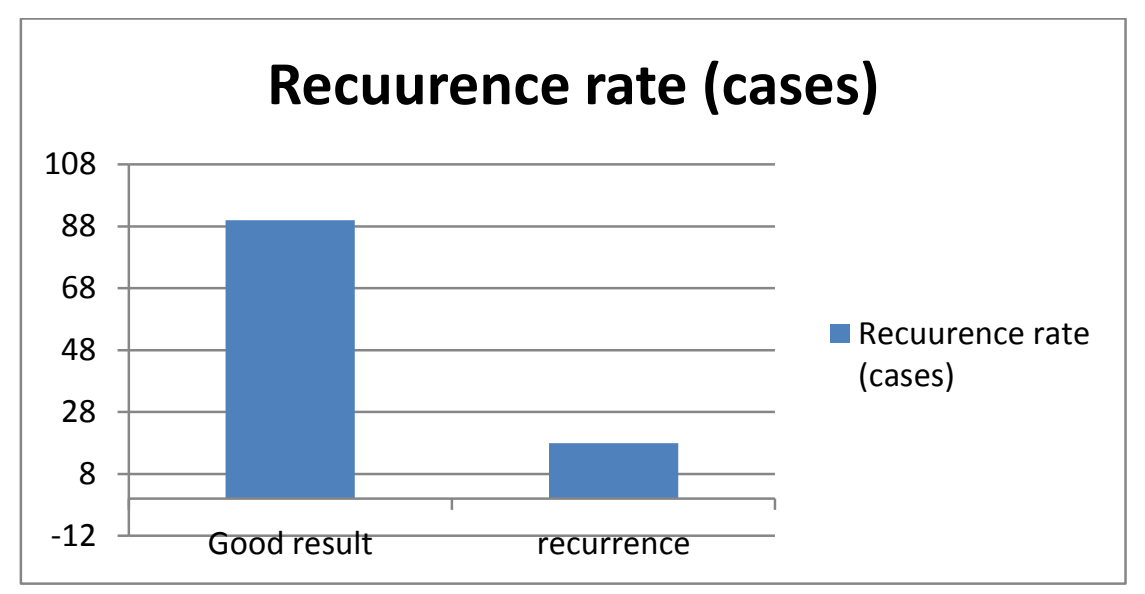

Fig (15): recurrence rate.

\section{Discussion}

Nail plate which causes ingrown nails develops and by lifting the lateral nail edge with cotton, acrylic from the nail matrix due to a process called balls, or nail splints ${ }^{\left({ }^{(}\right)}$. onychokeratinization. The matrix consists of 2 cell layers. The lower layer is the basal compartment, which contains germinative cells. The plate which grows here and extends to the distal adheres tightly to the nail bed beneath ${ }^{(5)}$.

Unfitting footwear and improper cutting of the nail destructs the lateral nail fold. With continuous toe movements, nail spicules are formed. The lateral nail fold is punctured with spicules, which move like foreign objects by burying themselves in the lateral nail fold ${ }^{(6)}$.

Mild erythema, edema, sensitivity, and pain along the lateral nail bed can be observed in early stages. This stage is called the inflammatory stage, in which success can be achieved with conservative treatments. With increasing erythema, edema, sensitivity, and pain, infection manifests itself. Protuberance develops on the lateral nail fold and nail plate, and with drainage development, the abscess stage follows. Granulation tissue covers the lateral nail fold preventing drainage. In this stage, the granulation stage, the epithelium begins to spread over the granulation tissue $1^{\left({ }^{(6)}\right.}$.

Successful results can be obtained with conservative treatment during the inflammatory stage and at the beginning of the abscess stage of ingrown nails. Treatment can be applied with appropriate foot care and correct nail cutting, systemic antibiotic use, the matrix using phenol. Recurrence rates were reported 
as $2.7 \%-24 \%$ following phenolization. Despite its effectiveness in treatment of ingrown nails, use of phenol also presents certain disadvantages. Phenol is a toxic substance that can easily be absorbed through skin. It should be neutralized with saline solution or glycolalcohol following its application. Diffuse damage might be seen in the surrounding tissue. Additionally, it may lead to delayed drainage and healing. Use of phenol is not recommended in pregnant patients ${ }^{(\mathbf{1 0})}$.

In a study which compared partial matrix excision and segmental phenolization for ingrown nails, 34 ingrown nails were treated with partial matrix excision following partial nail extraction, and 7 recurrences were reported. Seven recurrences were also reported in 29 ingrown nails which were treated with phenolization following partial nail extraction. In comparison of the 2 techniques, it was seen that partial matrix excision caused less postoperative morbidity and faster healing, and prolonged wound drainage was observed following phenolization. Recurrence rates were very high in both methods, though the preferred method was matrix excision, to avoid using phenol. Another study emphasized that the application area for phenol should be limited in treatment of ingrown nails ${ }^{(\mathbf{1 1})}$.

Chemical partial matricectomy with $10 \%$ sodium hydroxide or trichloroacetic acid was performed in some studies in an attempt to avoid the toxic effects of phenol. Recurrence rates reported in these studies are similar to those of phenol applications and were found as $2.4 \%$ and $5 \%$, respectively. Partial matricectomy with Carbon dioxide and laser was performed in 19 ingrown nails, and spicule occurrence was observed in 1 case $(5.5 \%)^{(12)}$.

The use of carbon dioxide laser in partial matricectomy application on 344 previously unsuccessfully treated ingrown nails resulted in delayed healing of up to 6 weeks, 5 recurrences, 14 spicules, and 8 infected nail folds. As presence of spicules should also be considered recurrence, the real recurrence rate was 19 cases $(5.5 \%)$. Of note, this system is technically challenging and expensive.

Cryotherapy is a local freezing application performed on live tissues with liquid nitrogen. Liquid nitrogen has the lowest boiling point among current freezing agents $\left(-196{ }^{\circ} \mathrm{C}\right)$ and is widely used in treatment of certain benign skin lesions. It is a fast and cost-effective treatment and is applied by spraying or with a probe on skin lesions. Different cells and tissues have different sensitivities to cold. In descending order, the cells most sensitive to cold are melanocytes, basal cells, and keratinocytes. It is reported that in order to treat skin lesions with a diameter of 5-25 mm, the cryotherapy device must be used at a distance of $10 \mathrm{~mm}$ from the skin lesion for $60-90 \mathrm{sec}$, and with this application $-50{ }^{\circ} \mathrm{C}$ will be reached at a depth of approximately $3 \mathrm{~mm}$. It was reported that this temperature is sufficient to kill the skin cells and shrinkage which develops in the application site in 1014 days, following cryotherapy, temporary edema, drainage, and maceration may be seen, and color changes in the application site and minimal scarring are common consequences. Cosmetic outcomes are in general favorable ${ }^{(\mathbf{1 3})}$.

Liquid nitrogen creates completely reversible functional changes in peripheral nerves. Because of this, it was reported that lesions can be treated without pain $^{(13)}$. Liquid nitrogen destroys pyogenic granuloma with its anti-infective and necrosis-developing characteristics due to the anti-infective effect of liquid nitrogen ${ }^{(13)}$, antibiotics were not used in any patients in the present study. Sonnex and Dawber ${ }^{(13)}$ treated 44 infected ingrown nails with granulation tissue via cryotherapy. The authors reported recurrence in 11 patients after nail avulsion, and 8 patients previously underwent unsuccessful lateral nail and matrix excision. The authors applied cryotherapy for $30 \mathrm{sec}$ from a distance of $10 \mathrm{~mm}$ to the infected granulation tissue and reported that the lesions healed in 4-5 days and many patients were able to discontinue dressing the wound in 1-2 weeks. Total treatment success rate was reported as $63.6 \%$ in $13-18$ month follow-up. The authors stated that this success rates could be increased by decreasing the nail bed volume or extending the freezing time. The reported rate of success is low. However, the authors did not perform matricectomy with cryotherapy, choosing to instead directly spray liquid nitrogen onto the infected granulation tissue ${ }^{(13)}$.

Our follow-up period in the present study was a minimum of 12 months. This period is sufficient to observe recurrence. The 108 cases, 90 ingrown nails had no recurrence and were satisfied with the appearance of their nails in general. Between 1 and 6-months followup, 18 nails, recurrence observed in the form of spicule growth in the nails. The limitations of our study were the lack of a comparison group and relatively high rate of inadequate follow- up of patients. In conclusion, soft tissue nail fold resection of ingrowing toenail without matrisectomy is considered an effective and safe method for ingrown nail treatment. Serous drainage seen postoperatively should be dressed frequently. Our procedure is a minimally invasive surgical approach with low recurrence rates, which should be supported further by more comprehensive studies.

\section{Conclusions}

Nail fold excision of ingrowing toenail without matrisectomy is considered as an effective and safe method for ingrown nail treatment. Serous drainage seen postoperatively should be dressed frequently. Our procedure is a minimally invasive surgical approach 
with low recurrence rates, which should be supported 7- Sonnex TS and Dawber RP (1985):

further by more comprehensive studies.

\section{References}

1. Rounding $C$ and Bloomfield $S$ (2005): Surgical treatments for ingrowing toenails. Cochrane Database Syst Rev.,2:CD001541.

2. Bostanci S, Koçyigit P, Gürgey E (2007): Comparison of phenol and sodium hydroxide chemical matricectomy for the treatment of ingrowing toenails. Dermatol Surg., 33:680-5.

3- Langford DT, Burke C, Robertson K (1989): Risk factors in onychocryptosis. $\mathrm{Br} \mathrm{J}$ Surg., 76(1):45-8.

4- Noël B (2008): Surgical treatment of ingrowing toenail without matricectomy. Dermatol Surg., 34:79-83.

5- Valazques EF and Murphy GF (2009): Histology of the skin. In: Elder DE, Elenitsas R, Johnson BL, Murphy GF, Xu X, editors. Lever's Histopathology of the skin. Philedelphia: Lippincott Williams \& Wilkins.

6- Tüzün Y, Kotogyan A, Severoğlu S (1993): Tirnakhastalıkları. İstanbul: Teknografik Matbaacilik.

https://www.journalagent.com/z4/download_ful ltext.asp?.
Treatment of ingrowing toenails with liquid nitrogen spraycryotherapy. Br Med J ., 291:1735.

8- Bostanci S, Ekmekçi P, Gürgey E (2001): Chemical matricectomy with phenol for the treatment of ingrowing toenail: a review of the literature and follow-up of 172 treated patients. ActaDermVenereol., 81(3):181-3.

9- Andrew T and Wallace WA (1997): Nail bed ablation-excise or cauterise? A controlled study. Br Med J., 1:1539.

10- Burns T, Breathnach S, Cox N, Griffiths C (2004): Surgical nail procedures. Rook's textbook of dermatology. Massachusetts: Blacwell Publishing Co .

11-Reyzelman AM, Trombello KA, Vayser DJ (2000): Are antibiotics necessary in the treatment of locally infected ingrown toenails? Arch Fam Med., 9:930-2.

12- Ozawa T, Nose K, Harada T (2005): Partial matricectomy with a carbon dioxide laser for ingrown toenail after nail matrix staining.DermatolSurg., 31:302-5.

13- Dawber R, Colver G, Jakson A (1997): Cutaneous Cryosurgery. London: Martin Dunitz.https://studylib.net/doc/7492029/patientinformation-leaflet---care-of-skin-after-cryo 